\title{
5 Experimental Research in the Densification of Wood Waste
}

In modern times, the used waste biomass from forests comes in different forms, like chips and shavings, sawdust, logs after logging, waste from manipulation in forest storage, tree stumps, roots, and other forms of waste. All these forms of waste are useful in generating thermal energy, i.e. the combustion in furnaces. For a more effective production of energy, the wooden waste should be processed into the more appropriate form, a compacted biofuel. With the modern boom in densification technologies, an important question to be answered is the question of material need. At the present time, we can already see that wood and wooden waste, of which there is an abundance, is lacking in practicality as biofuels. Furthermore, modern manufacturers of biofuels nowadays utilize rarely-used types of wood and often question the possibility of using other types of materials as a source of biofuel. These modifications include several factors to consider that the manufactures cannot ignore. The material properties of raw materials as well as the technological requirements of the production process itself must be considered. The input material must be disintegrated, dried, and pressed to secure optimal technological parameters that enable the production of briquettes with a desired density. If we look more closely on this process, it can be seen that each material demands its own procedure.

When pressing various types of material, different parameters (pressure, temperature, and others) are manipulated. There are operating differences between pressing soft woods and pressing hard woods. Of course, there can be differences between pressing soft woods of various types, and likewise with hard woods. Differences in chemical composition are not only present between deciduous trees and coniferous trees (Tab. 1.4), but also between each of the specific woods (Tab. 1.5). Using different types of raw material, and operating at different input conditions, the resulting briquettes possess different properties of various types (density, mechanical durability, thermal potential, water content, ash content).

To produce high-quality briquettes from each type of wood, it is necessary to understand the raw material behaviour. It is therefore very important to understand the behaviour of various materials during the process of densification and what technological parameters are to be controlled to produce a briquette with a certain standard of quality. Because each material has its own mechanical and thermal properties and a unique chemical composition, separate but similar experiments must be conducted for each of the wood types.

From the previous results and analysis, it is clear that the type of raw material used will have a significant influence on the pressing process. In the next phase of the present study, several experiments of similar character were conducted on several types of wooden materials. To maintain experimental accuracy, one material was 
tested at a time. In this chapter, the results from the experimental study of several types of wooden raw materials are discussed.
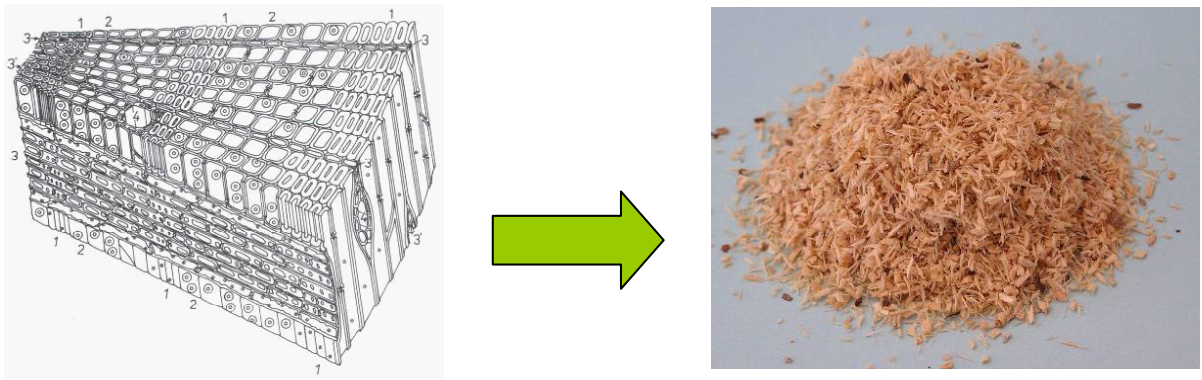

Figure 5.1: Spatial figure of softwood section (left) and spruce sawdust prepared for pressing (Požgaj \& et al., 1997; Križan \& et al., 2009).
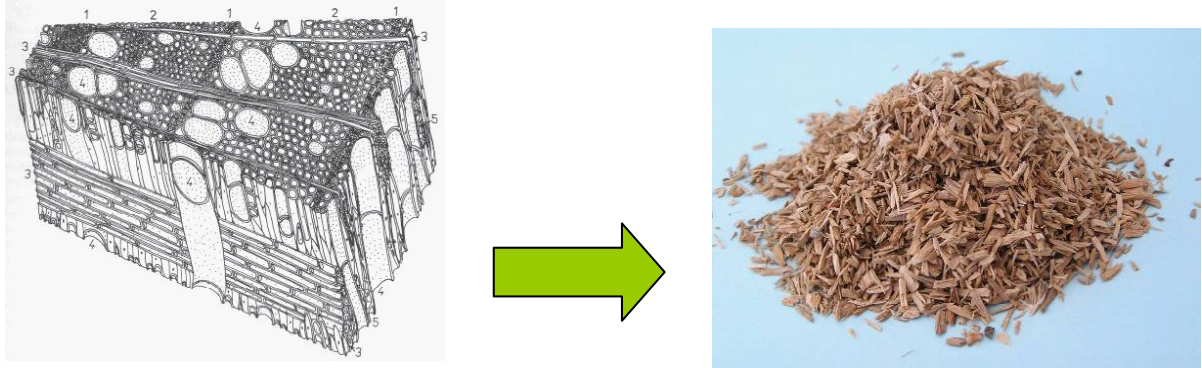

Figure 5.2: Spatial figure of hardwood (right) and beech wood sawdust prepared for pressing (Požgaj \& et al., 1997; Križan \& et al., 2009).

In the figures above, the difference between soft and hard wood is clearly seen. In Figure 5.1, the spruce sawdust is of $2 \mathrm{~mm}$ fractions. In comparison with Figure 5.2, which shows the same fraction size of beach wood sawdust, it can be seen that the structure and shape of the two types of wood particles are different. In this case, spruce sawdust has a very fine structure, resembling a cluster of fine particles, or flakes. Beech wood sawdust shows the character of hard, long flakes. These differences cause different behaviours in the raw material when compressed. 


\subsection{Experimental Research on Selected Types of Wood}

All experiments were conducted in a similar manner on an experimental pressing stand. As previously mentioned, on this stand, it is possible to conduct experiments to determine the effect of pressing temperature, pressing pressure, material moisture, the size of input fraction, and the effects of some of the structural parameters. The experiments were conducted at ambient temperature, around $23^{\circ} \mathrm{C}$. The experimental plan was identical to the plan of the pine sawdust experiment. In this phase of the study, spruce sawdust, beech wood sawdust, and oak sawdust were used. The input fractions of the mentioned materials, compared to that of the pine sawdust, are shown in the following figure.

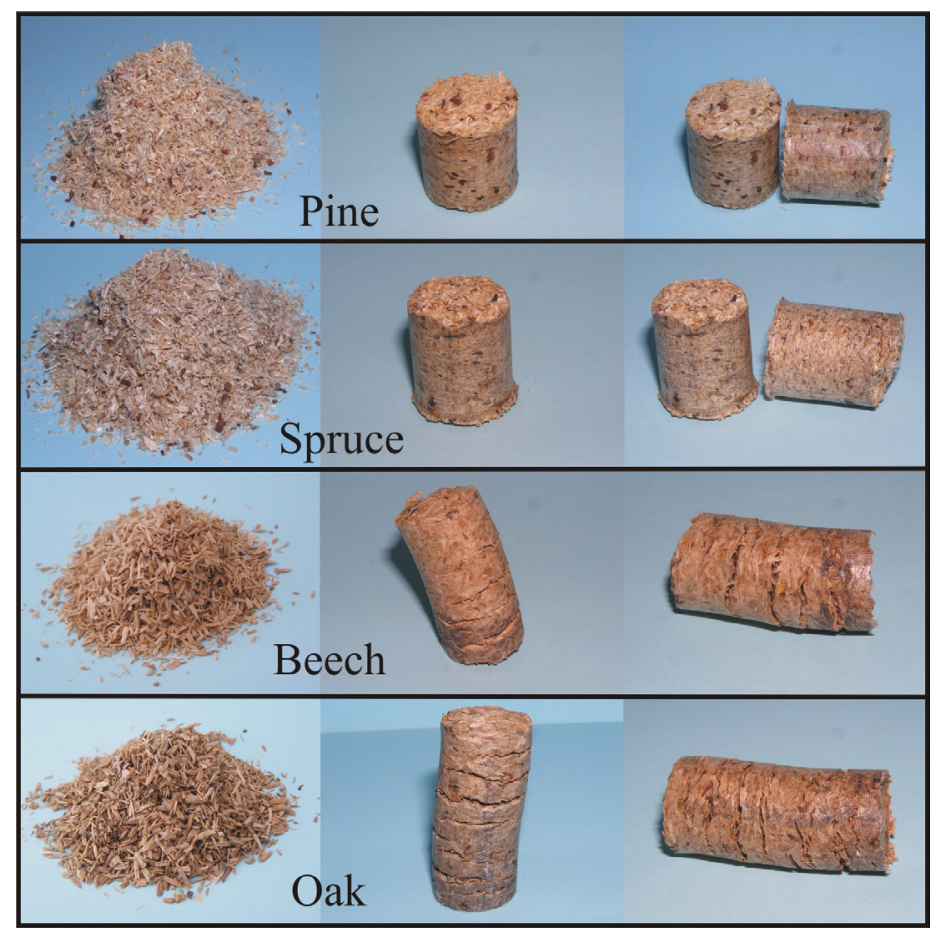

Figure 5.3: Input fraction (sawdust) and briquettes of various materials (Križan \& et al., 2009; 2011a).

The next figure shows the relationship between the effects of the pressing temperature and pressing pressure on the resultant density of the spruce briquettes. Pressing pressure is a factor that mainly affects the strength of the briquette. Briquette strength is higher when the acting pressure is higher during compression. It increases to the 
ultimate tensile strength of the compressed material. The briquette strength affects the durability of the briquettes because the increased strength decreases the tendency of the final product to absorb atmospheric humidity when stored.

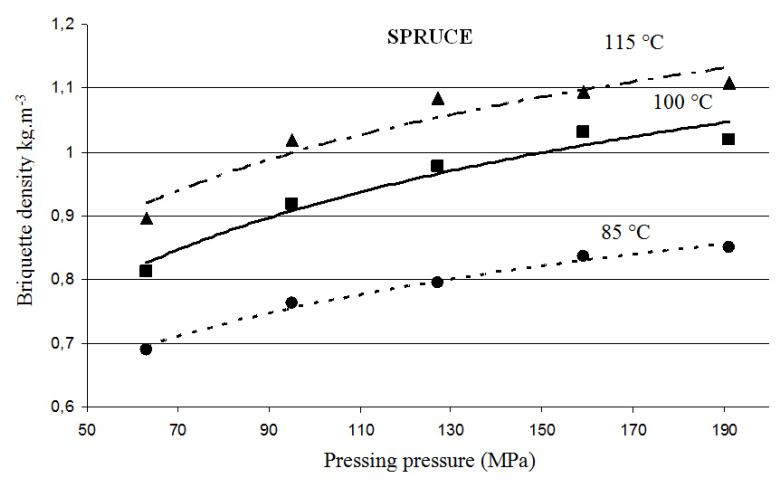

Figure 5.4: Dependence of briquette densities of spruce on the pressing pressure at different pressing temperatures. ( $w_{r}=10 \% ; L=2$ mm) (Matúš \& Križan, 2010; Menind \& et al., 2012; Križan, 2007).

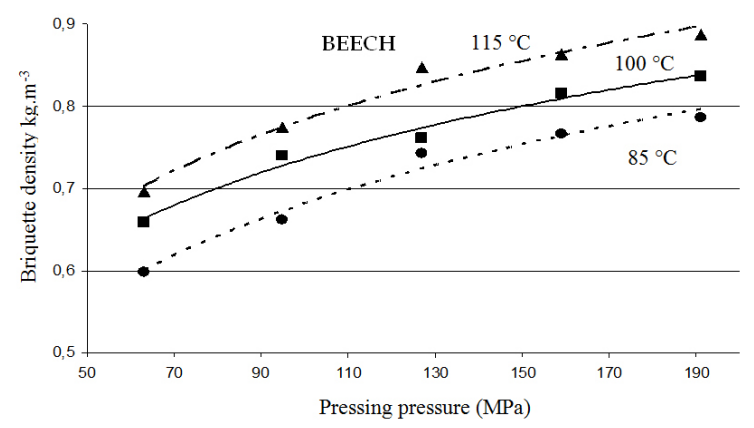

Figure 5.5: Dependence of briquette density of beech on the pressing pressure at different pressing temperatures. $\left(w_{r}=10 \%\right.$; L 2 mm) (Matúš \& Križan, 2010; Menind \& et al., 2012; Križan, 2007).

The depicted relationship proves that, for hardwood raw material (beech, oak), with increasing pressing temperature improves the density of the resultant briquettes. This trend is also true for increasing pressing pressure. 


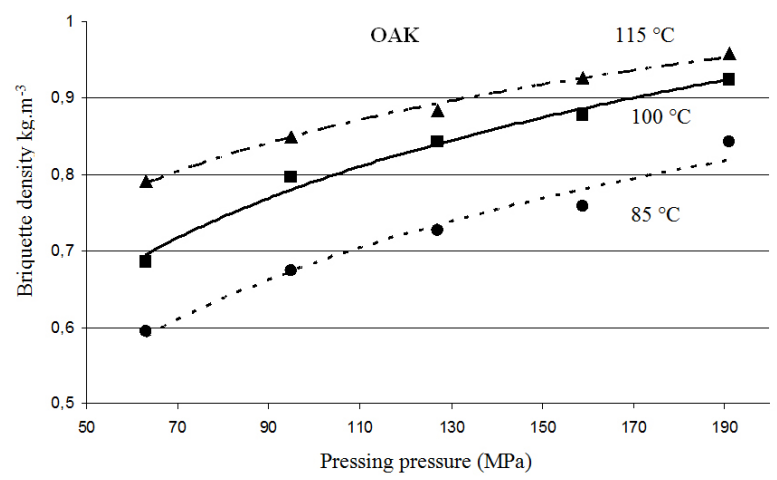

Figure 5.6: Comparison between briquette density of oak and its dependency on pressing pressure at various pressing temperatures ( $w_{r}=10 \% ; L=2 m m$ ) (Matúš \& Križan, 2010; Menind \& et al., 2012; Križan, 2007).

The aforementioned dependencies prove the affect of pressing temperature on various materials. We observe that each material behaves differently; thus, it is crucial to set the conditions properly to meet the product requirements during the densification process. The higher the pressing temperature, the lower the needed pressing pressure needed to achieve a standard briquette quality. Pressure and temperature mutually influence each other during the densification process; if the pressure is increased, we can slightly decrease the temperature, and vice-versa.

We can observe that, while pressing hardwood (beech, oak), achieving a briquette density of $1 \mathrm{~kg} \cdot \mathrm{dm}^{-3}$ failed. This failure is perhaps due to the fact that these woods do not have a large lignin content as softwood does. For softwood, the lignin content is much higher, which causes better bonding between the material particles and thus better compression. It is necessary to note that, for hardwood, a negative factor is the fact that the pressed fraction is of size $2 \mathrm{~mm}$. By reducing the size of the fraction, it is possible to achieve the standard briquette density for all examined materials. Additionally, the mutual interaction between the pressing temperature (increase) and the moisture change of the pressed material has, according to the presented results, the most significant effect on the densification process of wooden materials. The measured results from spruce, beech, and oak sawdust, were evaluated and incorporated into a mathematical model. The designed mathematical models are valid only for the specific materials and observed parameters that can be changed in intervals in which the experiments were conducted. 


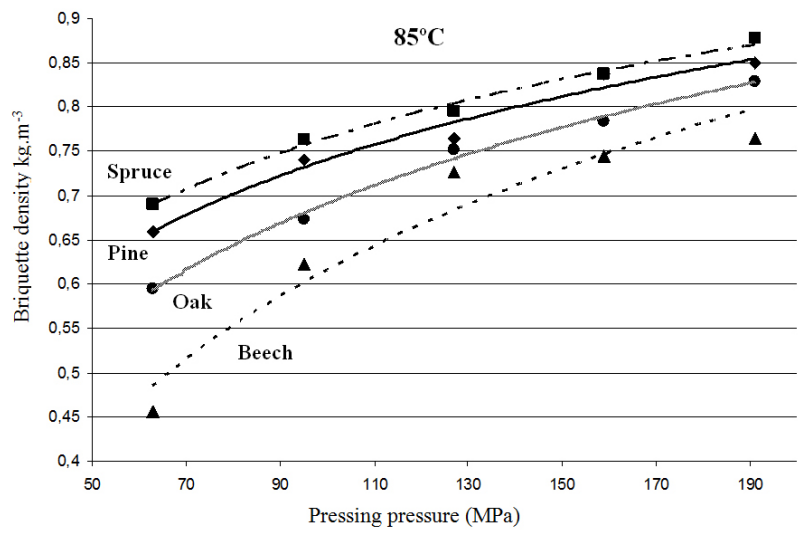

Figure 5.7: Comparison between briquette density depending on various materials to pressing pressure at a pressing temperature of $85^{\circ} \mathrm{C}\left(\mathrm{w}_{\mathrm{r}}=10 \% ; \mathrm{L}=2 \mathrm{~mm}\right)$ (Matúš \& Križan, 2010; Menind \& et al., 2012; Križan, 2007).

In Fig.5.7, the measured dependencies of each of the woods at a pressing temperature of $85^{\circ} \mathrm{C}$ are shown. It is clear from the graph that the temperature is too low for the optimal plasticization of lignin and for bonding of the lignin to the material particles under the effect of an external load. The resulting briquettes, even at a pressing pressure of 191 $\mathrm{MPa}$, do not meet the standard density. It can also be observed that the dependencies have an expected course with respect to the wood compression parameters; at low temperatures, the bonding and attracting forces between the particles are significant. The function of lignin is similar to that of glue, and although it is not negligible, in this case it is secondary. From the graph, the behaviour of spruce and pine during the process of compression can be observed. The dependencies suggest that a higher content of lignin affects the briquette density.

In Fig. 5.8, it can be seen that the increase of pressing temperature has an effect on the higher value of briquette density at a lower pressing pressures. For spruce and pine, we notice a significant increase in density at higher pressures. Even though the pressing temperature is not yet optimal, a higher lignin content is present in these materials. For oak and beech, the increase of density is slower due to the much lower content of lignin. Even at a temperature of $100^{\circ} \mathrm{C}$ combined with a higher pressing pressure of $191 \mathrm{MPa}$, optimal plasticization of lignin is not reached in hardwood.

In the next figure, the dependencies of briquette density from various materials on the pressing pressure (at a pressing temperature of $115^{\circ} \mathrm{C}$ ) show that, for softwood, the role of higher lignin content improves the bonding of material particles for better compression. For hardwood, in which lignin is less abundant, lower briquette density values are achieved. The figure not only depicts the difference between soft and hard wood but also between each wood type as well. A solution to increase briquette 
density from the point of view of biofuel production technology is the use of additives. Technical standards permit the use of glues, but of course only the ones based on biologically friendly materials. Here, we associate the chemically unmodified products with agricultural and forest biomass (for example, whole grain flours, cornstarch, and rye flour). These can be mixed with basic materials to produce wooden pellets and simplify the pressing process while also improving the energy balance, density, and mechanical resistance of the resulting briquettes.

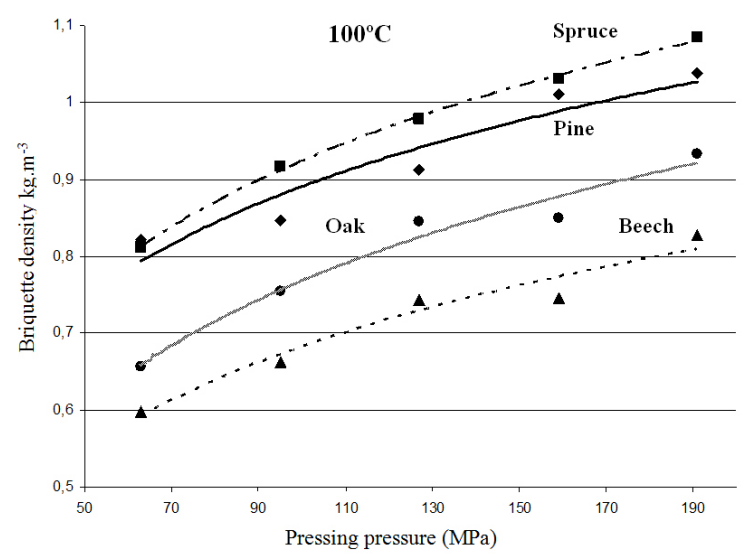

Figure 5.8: Comparison between the dependencies of briquette densities and pressing pressures at a pressing temperature of $100^{\circ} \mathrm{C}$ of various materials $\left(w_{r}=10 \% ; L=2 \mathrm{~mm}\right.$ ) (Matúš \& Križan, 2010; Menind \& et al., 2012; Križan, 2007).

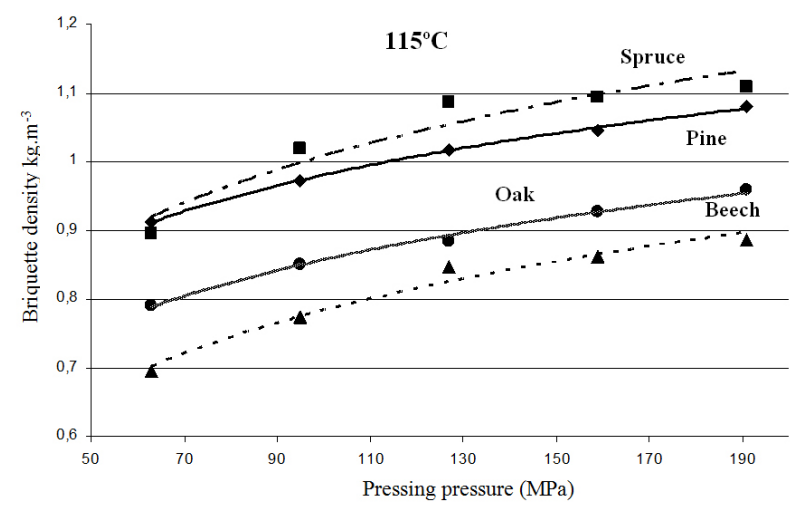

Figure 5.9: Comparison of briquette density, dependencies of various materials to the pressing pressure at a pressing temperature of $115{ }^{\circ} \mathrm{C}\left(w_{r}=10 \% ; L=2 \mathrm{~mm}\right)$ (Matúš \& Križan, 2010; Menind \& et al., 2012; Križan, 2007). 
We see that the increase in pressing temperature has a positive effect on the performed experiments. The most significant effect on the process is the pressing temperature. Although the evaluations mentioned in this monograph were discussing the compression of pine sawdust only, it is highly probable that the pressing temperature will have the most significant influence on the briquette density for various wooden materials.

\subsection{Experimental Research on the Effect of Parameters on Briquette Dilation}

Experiments in the field of biomass densification indicate that briquette dilation is a very important factor to be considered (Križan \& et al., 2014; Simanov, 1995). Briquette dilation is a phenomenon during which, under the effect of internal briquette parameters and external process parameters, the dimensions of the briquette (diameter, length, and briquette weight) change. Regarding the process and evaluation of the experiments, it is not possible to measure briquette dimensions directly after pressing. Dilation thus directly affects the given briquette parameters. The process of dilation arises under the effect of pressure and in relation to mutual interaction of pressing temperature, input fraction size, and material moisture content. For the purposes of experimentation, we distinguish two basic types of briquette dilation (Križan \& et al., 2014; Križan, Šooš \& Matúš, 2011):

- dilation with the effect of decreasing briquette density - as the briquette diameter increases, the length of the briquette increases and the weight of the briquette decreases (the accompanying phenomena cause the formation of cracks in the briquette, where material particles are separated or the briquette falls apart).

- dilation with the effect of increasing briquette density - as the briquette diameter decreases, the briquette length decreases and the weight increases (the accompanying phenomena is the briquette retracting and hardening).

Both these basic types of dilation are, of course, significantly affected by the types of compressed material, the moisture content of the input fraction, its size, the pressing temperature, the pressing pressure, and the length of briquette relaxation time.

Briquette stabilization period is the time interval during which dilation of the briquette occurs and during which the briquette is stabilizing (Križan \& et al., 2014; Simanov, 1995). The stabilization period of the biomass briquette takes around 24 hours depending on the type of material and technology used, although it can take even longer. After pressing, the briquette is placed into stable environmental conditions. During this stabilization period, the diameter, length, and weight are measured multiple times and evaluated. If, during the course of the 24 hour period, the weight of briquette changes by a maximum of $0.1 \%$ of its weight, the state of the briquette is considered stabilized (DIN 52182). 
The stabilization period (briquette dilation) is significant mainly regarding the change in briquette density. Briquette density is one of the basic mechanical indicators of briquette quality, which is why the final product densities are determined after each experiment. The density is important regarding the sufficient coherence of material particles in the briquette. Therefore, it is important to consider the dilation during experiments and obtain data over a period from the fresh briquette to the stabilized briquette. During biomass densification, lignin is released, which acts as a glue. At the same time, it creates a layer or thin film on the surface of the product that prevents moisture from being absorbed from the surroundings. The effect of dilation is well known for briquette producers. During real operations, non-acceptable effects of briquette dilation may occur and lead to crumbling. In technological production lines, the standard stabilization duration is shortened by cooling the briquettes. During laboratory experiments, dilation can significantly distort the results.

\subsubsection{The Effect of Pressing Pressure on Briquette Dilation}

Al relations presented in this monograph from the included experimental results are shown after the stabilization period. Results can be evaluated and processed only after briquette stabilization. On the following figure, the differences between pinewood briquettes before and after stabilization are shown. The difference is significant. To obtain a correct result, it is necessary to work with results obtained only after stabilization.

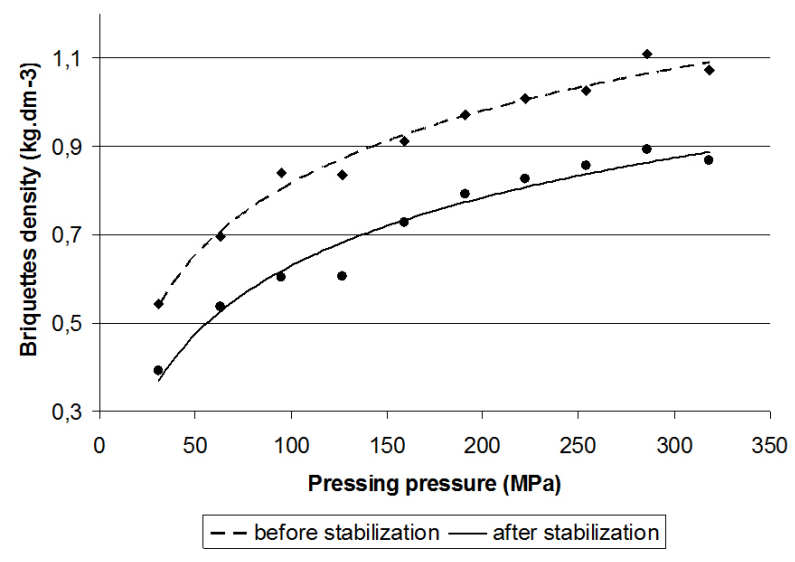

Figure 5.10: The briquette density of Pine sawdust, dependence of the pressing pressure $\left(w_{r}=10 \%\right.$; $\mathrm{L}=2 \mathrm{~mm}$ ) (Križan \& et al., 2014).

An experimental objective was to quantify and define the effect of basic technological parameters on briquette dilation. The experimental research was conducted on 
a designed experimental pressing stand according to the procedure described and mentioned in the previous chapter. The briquette density was chosen as an indicator of quality. For each point shown in the graphical dependencies, ten briquettes were created. This number of briquettes was chosen to obtain more accurate data and decrease the result error. The experiments were performed with pine sawdust with a fraction size $2 \mathrm{~mm}$ and moisture content of $10 \%$. These material parameters where sustained throughout all of the experiments. On the basis of analysis conducted in our workplace and on the basis of information gained from several and various international conferences and symposiums, we defined the effect of pressing pressure and the effect of pressing temperature on briquette dilation.

In the first step, the effect of pressing pressure was defined. In the following table, the average values of briquette density compressed at various pressures are listed. Calculated briquette densities and the differences before and after stabilization are also shown. The biggest difference in briquette density was noted at lower pressing pressures. With theincrease of pressing pressure, these differences slightly diminished. The trend shows that, the higher the pressing pressure is during the process, the lower the briquette dilation. In Fig. 5.11, the difference in briquette density before and after stabilization for each briquette is shown at various pressing pressure settings.

In Tab. 5.1, the average density values are listed. These average values were calculated from a set of 10 densities. These are shown separately in Fig 5.11.

Table 5.1: Briquette density from Pine sawdust in relation to pressing pressure $\left(w_{r}=10 \% ; L=2 \mathrm{~mm}\right)$ (Križan \& et al., 2014).

\begin{tabular}{lllll}
\hline Briquette no. & Pressure & $\begin{array}{l}\boldsymbol{\rho}\left(\mathrm{kg} / \mathrm{dm}^{3}\right) \\
\text { Before } \\
\text { stabilization }\end{array}$ & $\begin{array}{l}\text { After } \\
\text { stabilization }\end{array}$ & $\begin{array}{l}\text { Density } \\
\text { difference }\end{array}$ \\
\hline $\mathbf{1 .}$ & $\mathbf{M P a})$ & 0.664 & 0.350 & $47 \%$ \\
\hline 2. & 31 & 0.699 & 0.535 & $23 \%$ \\
3. & 63 & 0.841 & 0.605 & $28 \%$ \\
4. & 95 & 0.836 & 0.625 & $25 \%$ \\
5. & 127 & 0.913 & 0.729 & $20 \%$ \\
6. & 159 & 0.967 & 0.792 & $18 \%$ \\
7. & 191 & 1.066 & 0.813 & $24 \%$ \\
8. & 222 & 1.026 & 0.856 & $17 \%$ \\
9. & 254 & 1.113 & 0.893 & $20 \%$ \\
10. & 286 & 1.074 & 0.869 & $19 \%$ \\
& 318 & & & $\mathbf{\Delta}=\mathbf{2 4 \%}$ \\
\hline
\end{tabular}


The relationships in the previous figures prove the tendency of briquette dilation to decrease under increasing pressing pressure. It was also demonstrated that selecting a high number of briquettes for one setting decreases the resulting error. It can be seen that some of the measured values are significantly different than that of the averaged one.

\subsubsection{The Effect of Pressing Temperature on Briquette Dilation}

A similar experiment was performed to determine the effect of the pressing temperature on briquette dilation. The configuration and conditions of the experiments were left the same as in the previous case, but we observed changes not only at a temperature of $25^{\circ} \mathrm{C}$ (laboratory conditions), but also at temperatures of $80^{\circ} \mathrm{C}$ and $115^{\circ} \mathrm{C}$.

In the previous figure, the effect of pressing temperature on briquette density can be observed. With increasing pressing pressureand pressing temperature, the briquette density increases. It is important to note that the values presented on this figure are measured after stabilization. The effect of pressing temperature and pressing pressure on briquette density was defined and quantified just like in previous chapters. And, as it was mentioned before in this monograph, pressing temperature during densification of wooden materials goes hand in hand with the pressing pressure. In the next figure, the dependency between the pressing temperature and pressing pressure regarding the briquette density are shown.

Temperature significantly affects the bonding mechanism acting between the solid particles of the pressed material. A more thorough bonding of cellular structure of pressed material and the required plasticization of lignin is possible only under the active pressing temperature. In the case of pressing at an improper temperature, Van der Waals attraction forces form between the solid material particles. On the basis of decreasing the gaps between the solid particles of the material, and because the moisture within the pressed material is contained mainly on the product surface, fluid bridges start forming. Particles get closer to each other and are pressed as a result of the acting pressing pressure, and on the basis of their shape, they connect and bind together to create deformed bonds. Wood is an elastic material; to overcome its elastic limit, optimal conditions for bonds to form between particles must be achieved. At pressing conditions, where the pressing temperature was maintained at $25^{\circ} \mathrm{C}$, these bonds were not created; after releasing pressure, the briquette changed its dimensions and "inflated." This phenomenon causes a lower briquette density after stabilization than before stabilization (Fig. 5.10). The average density change of pinewood briquettes at a pressing temperature of $25^{\circ} \mathrm{C}$ was $24 \%$ (Tab. 5.1). 
$31 \mathrm{MPa}$

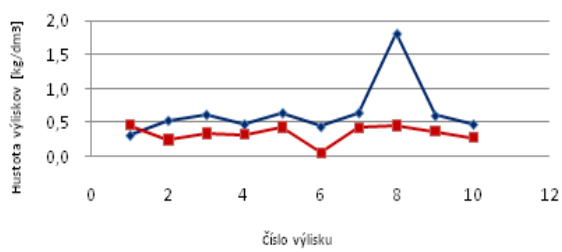

$$
\text { —— predstabilizáciou ——- postabilizácii }
$$

$95 \mathrm{MPa}$
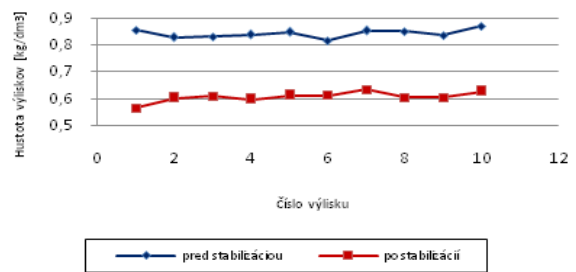

$159 \mathrm{MPa}$
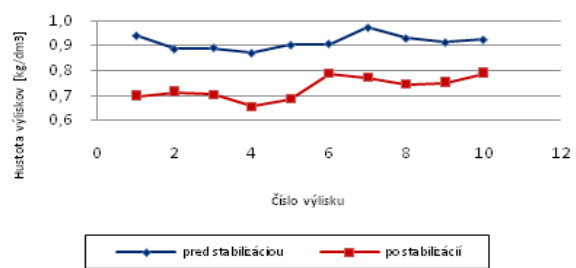

$222 \mathrm{MPa}$

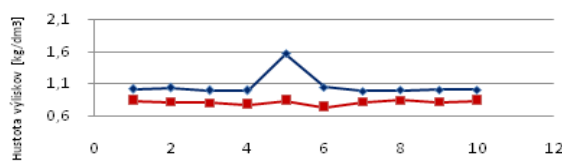

Čislo výlisku

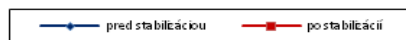

$286 \mathrm{MPa}$

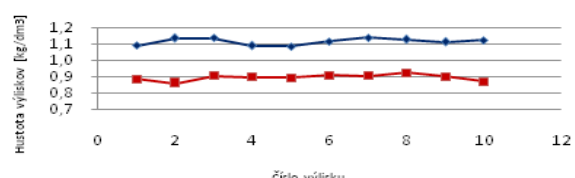

Čislo výlisku

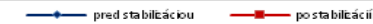

$63 \mathrm{MPa}$

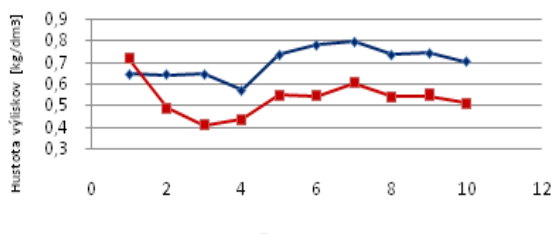

čislo výlisku

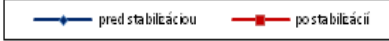

$127 \mathrm{MPa}$

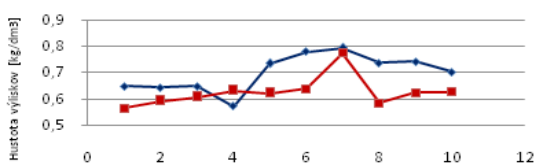

Číslo výlisku

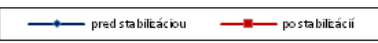

$191 \mathrm{MPa}$

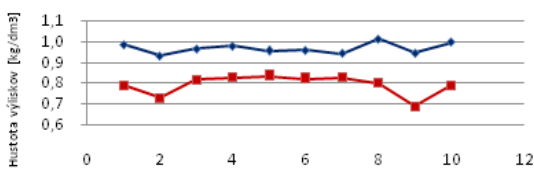

Čislo výlisku

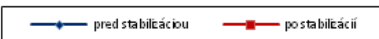

$254 \mathrm{MPa}$

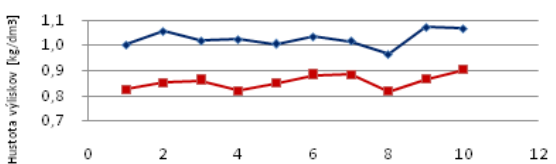

čislo výlisku

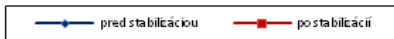

$318 \mathrm{MPa}$

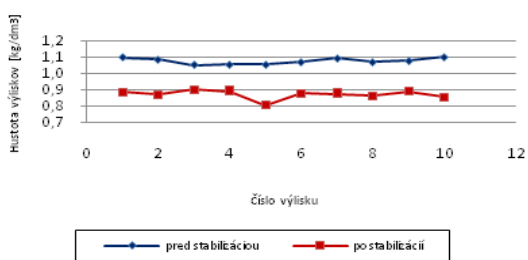

Figure 5.11: Dilation process, briquette density values at various pressures (relation description: axis $x \rightarrow$ briquette number; axis $y \rightarrow$ briquette density $\left(\mathrm{kg} / \mathrm{dm}^{3}\right)$; blue color $\rightarrow$ before stabilization ; red color $\rightarrow$ after stabilization); (Križan \& et al., 2014; Križan, Šooš \& Matúš, 2011). 


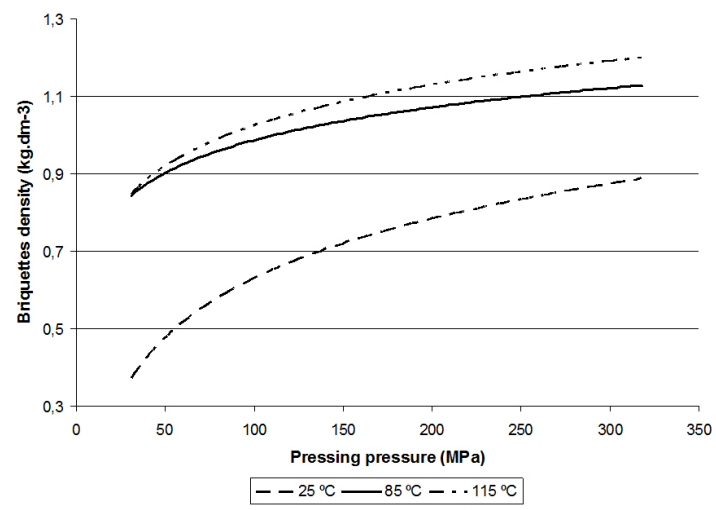

Figure 5.12: Density of Pinewood briquettes, dependence of the pressing temperature at various pressing temperatures. ( $w_{r}=10 \% ; L=2$ mm) (Križan \& et al., 2014; Križan, Šooš \& Matúš, 2011).

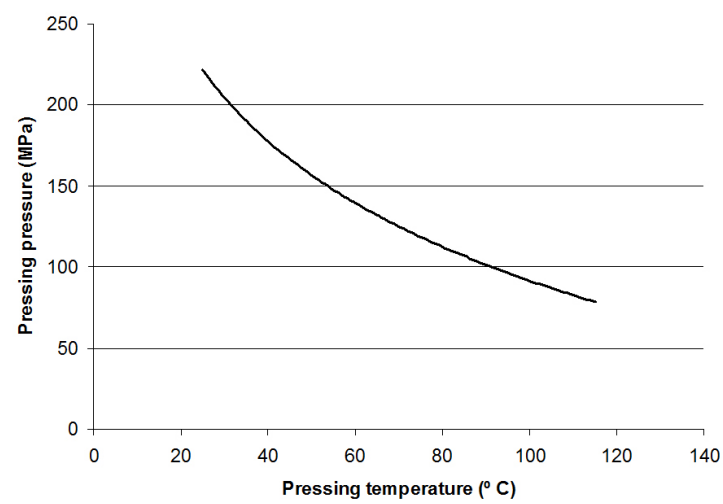

Figure 5.13: Pressing pressure, dependence of the pressing temperature when pressing Pine sawdust. (Križan \& et al., 2014; Križan, Šooš \& Matúš, 2011).

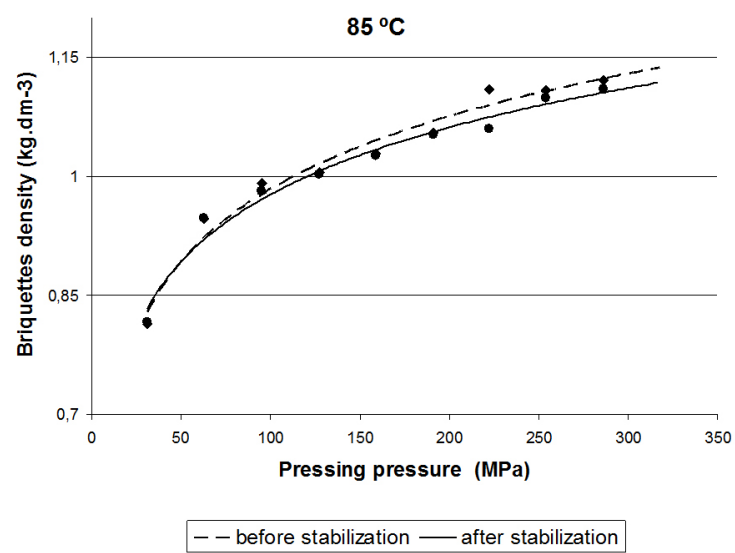

Figure 5.14: Briquette density of Pine sawdust, dependence of the pressing pressure at $85{ }^{\circ} \mathrm{C}\left(\mathrm{w}_{\mathrm{r}}=10 \%\right.$; $\mathrm{L}=2 \mathrm{~mm}$ ). 
In the previous figure, the dependence of briquette density on the pressing pressure at a temperature of $85{ }^{\circ} \mathrm{C}$ is shown. The differences between the curves, which compare the states before and after stabilization, decrease. The briquette density before stabilization decreased by $1.5 \%$ compared to the state before stabilization. This is a significant difference compared to briquettes pressed at $25^{\circ} \mathrm{C}$. This can be attributed to the effect of higher pressing temperature. In this case, better bonding between material particles and a certain phase of lignin plasticization has been reached. However, the briquette still lacks sufficient internal strength, which prevents its disintegration and thus decreases the briquette density.

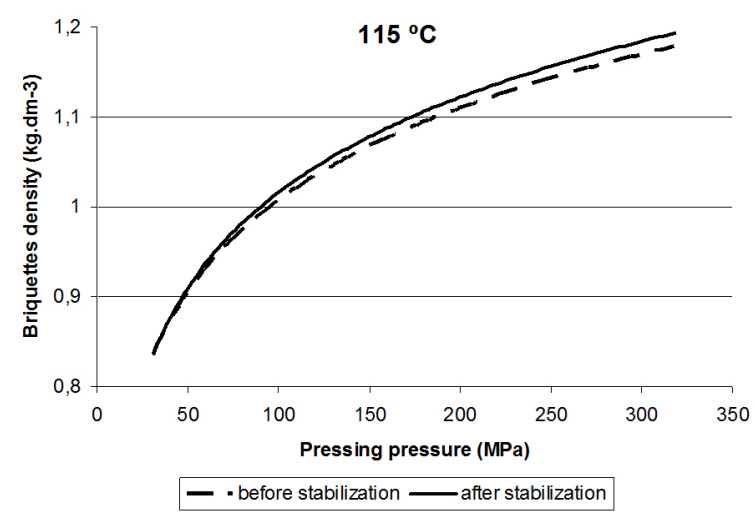

Figure 5.15: Briquette density of Pine sawdust, dependence of the pressing pressure at $115^{\circ} \mathrm{C}\left(\mathrm{w}_{\mathrm{r}}=\right.$ $10 \% ; \mathrm{L}=2 \mathrm{~mm})$.

The dependence of the briquette density on the pressing pressure at a pressing temperature of $115 \circ \mathrm{C}$ is shown in the previous figure. The difference between the curves before and after stabilization is once less than that of the previous cases. An interesting phenomenon is that, after stabilization, a higher value of density than that before stabilization is reached. For briquettes compressed at this temperature, there is no expansion or disturbance to the briquette's structure occurring during dilation; on the contrary, the briquettes are compacted, and after stabilization, a higher density is reached.

The previous results indicate the effect of pressing temperature on briquette dilation. Thus, with increasing pressing temperature, the briquette density decreases. Interesting is the comparison at which pressure the density of $1.12 \mathrm{~kg}^{-\mathrm{dm}^{-3}}$ (stated by the standard DIN Plus) was reached. At a pressing temperature of $25{ }^{\circ} \mathrm{C}$ (Fig. 5.10), this value was not reached; at a pressing temperature of $85^{\circ} \mathrm{C}$ (Fig. 5.14), the desired density was reached at a pressure of $220 \mathrm{MPa}$. Finally, at a pressing temperature of 115 oC (Fig. 5.15), the given density was reached at a pressure of $190 \mathrm{MPa}$. Thus, if we press at a higher temperature, we can use less pressure to achieve the required briquette 
density. A higher pressing pressure is more appropriate, since better molecular bonding is achieved in the material because of the lignin plasticization.

Of course, the listed pressure values are very high. It is necessary to press briquettes at a lower pressing pressure. It is therefore important to define and quantify the optimal conditions for several wooden materials and thus decrease the requirements for constructing the pressing equipment. One method might be by increasing the pressing temperature to a maximum value of around $130 \stackrel{\circ}{\circ}$. Increasing the temperature higher than that results in the loss of volatile substances and lignin.

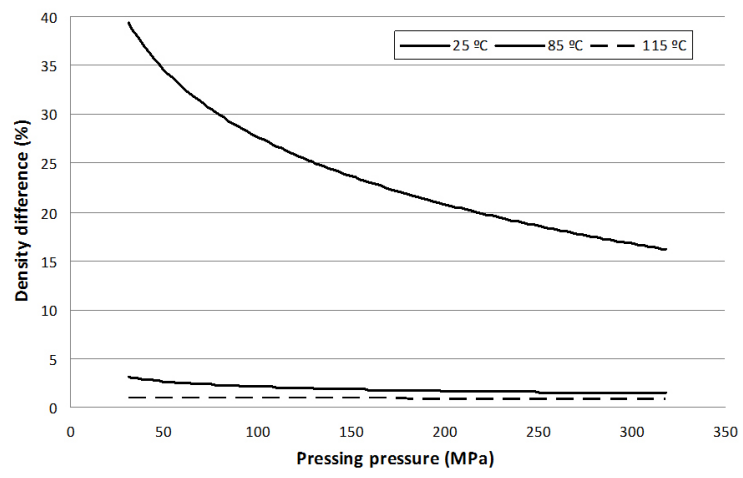

Figure 5.16: Density differences, dependence of the pressing pressure at observed temperatures. (Pine sawdust; $\mathrm{w}_{\mathrm{r}}=10 \%$; L = $2 \mathrm{~mm}$ ) (Križan \& et al., 2014; Križan \& et al., 2011b).

In the previous figure, the dependence can be seen between different densities of pine sawdust briquettes on the pressing pressure at three observed temperatures $\left(25^{\circ} \mathrm{C}\right.$, $85^{\circ} \mathrm{C}$, and $\left.115^{\circ} \mathrm{C}\right)$. These dependencies clearly show the effect of increasing pressing pressure together with temperature on briquette dilation. We can see that increasing the pressing pressure without the effect of temperature positively affects the briquette dilation.

\subsubsection{The Effect of Fraction Moisture on Briquette Dilation}

In the next phase of the experimental research, the objective was to define the effect of fraction moisture on briquette dilation. In this case as well, pine sawdust of size 2 $\mathrm{mm}$ was used. The experiments were conducted in a similar manner as before. Since the objective was to determine the effect of moisture content, 8 levels of configuration for monitored parameters were equally distributed over a range of 5\% to $30 \%$. For each level, 10 briquettes were pressed. The pressing pressure was constant and set at $286 \mathrm{MPa}$. Since we were pressing without increasing temperature, this pressing 
pressure was selected to achieve briquette compactness. In the following figure, we can see the dependency of briquette density on moisture fraction. The two curves represent the states before and after stabilization. The briquette density difference is significant before and after stabilization, and the average difference in pine sawdust briquettes is around $9 \%$.

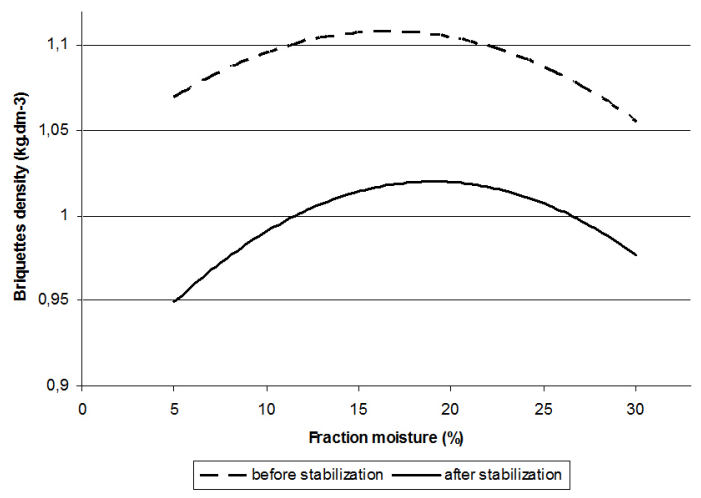

Figure 5.17: Briquette density, dependence of Pine sawdust on the moisture content in the fraction (p = 286 MPa; L = 2 mm) (Križan \& et al., 2014; Križan \& Matúš, 2008).

In the following figure, the dependence of briquette density on the moisture content of input fractions is shown. We can observe that, with increasing moisture, the density has a tendency to decrease. It is necessary to note that these results were obtained while pressing without any input temperature. It was thus interesting to compare the results of density change after using higher temperatures. As was previously quantified in the experimental research (Fig. 3.14), the interaction between pressing temperature and moisture fraction has a significant effect on the resultant briquette density.

Other than that, increasing the pressing temperature positively increases the briquette density and also tends to decrease the negative effect of moisture fraction on the briquette density. This statement also proves the listed results in Fig. 4.4. Under a temperature of $85^{\circ} \mathrm{C}$, the increase in briquette density when changing the moisture content from $12 \%$ to $8 \%$ results in an almost tenfold difference, as when operating at a temperature of $115^{\circ} \mathrm{C}$. Based on this, we can assume that the listed interaction (pressing temperature $\leftrightarrow$ fraction moisture) will have an effect on briquette dilation. Thus, in the future it is necessary to perform experimental research with the objective of defining the effect of the interaction (pressing temperature $\leftrightarrow$ fraction moisture) on briquette dilation. Also, it will be important to perform research on various types of wooden materials, since the effect of the given interaction is related to the lignin and cellulose content in the materials. 


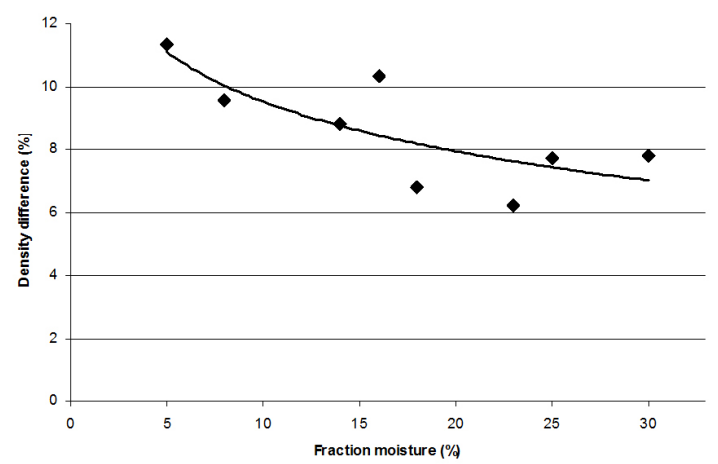

Figure 5.18: The difference of briquette density on moisture content of input fraction ( $\mathrm{p}=286 \mathrm{MPa}$; L = 2 mm) (Križan \& et al., 2014; Križan \& et al., 2011b).

\subsubsection{The Effect of Fraction Size on Briquette Dilation}

A significant part of the experimental research was also studying the effect of fraction size on briquette dilation. The experimental results in Fig. 4.5 have shown that decreasing the fraction size can positively influence the increase in briquette density. Therefore, it was important to also define the effect of fraction size change on briquette dilation. The experimental conditions were similar to those of the previous experiment when observing the effect of fraction moisture on briquette dilation. In the following figure, the dependence of briquette density on fraction size is shown. Again, the two curves characterize the state before and after stabilization. The briquette density difference before and after stabilization is very significant; the average change in density of pinewood briquettes is around $18 \%$.

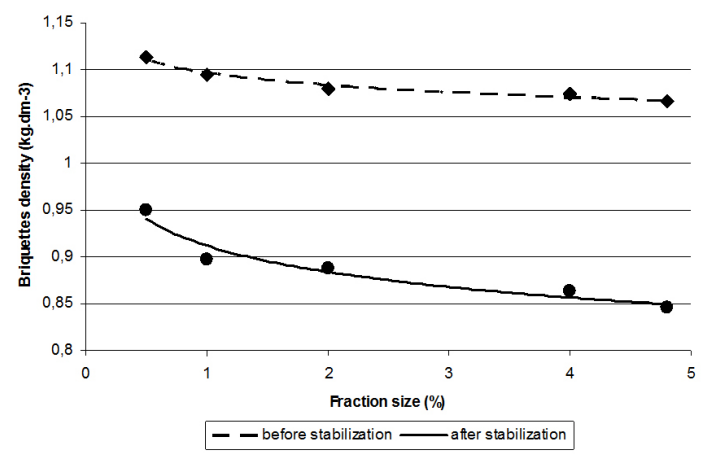

Figure 5.19: Dependence of Briquette density (Pine sawdust) on fraction size ( $p=286 \mathrm{MPa} ; \mathrm{L}=2 \mathrm{~mm}$ ) (Križan \& et al., 2014; Križan \& et al., 2011b). 
In the figure, it can be observed that, with increasing fraction size, material density changes. Also, it is important to note that, for these experiments, the measurement was performed while pressing without any increase in temperature during the process and at a constant pressing pressure. It is interesting to compare the results of briquette density change obtained by pressing at higher temperatures and with various levels of pressure.

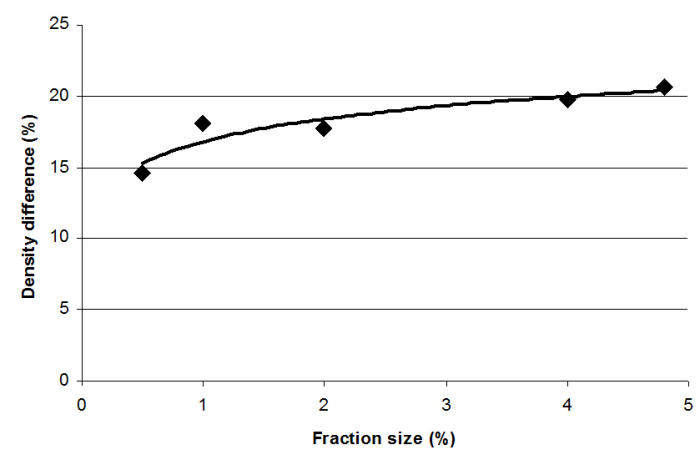

Figure 5.20: The difference in briquette density depending on fraction size ( $p=286 \mathrm{MPa} ; \mathrm{L}=2 \mathrm{~mm})$ (Križan \& et al., 2014; Križan \& et al., 2011b).

The sawdust compressibility factor size is also an important parameter. The compressibility factor characterizes one of the basic properties of disintegrated sawdust - compression. The sawdust compression is defined as the tendency of bulk sawdust to change volume under the effect of an external force. This means that the magnitude of this compressibility or compression factor is affected by the acting pressure. The results of the experiments show that increasing the pressing pressure for sawdust of equal fraction size increases the briquette density. Also, it is shown that, by increasing the fraction size, the briquette density decreases (Fig. 5.21). The listed results imply that important parameters affecting the compression factor are the pressure and the fraction size. Also, experimental research determined that, by increasing the size of the fraction under the same pressure, the compression factor decreases. Thus, it is important to conduct experimental research with the objective of defining the affect of the interaction (pressing pressure $\leftrightarrow$ fraction size) on briquette dilation in the near future (Matúš \& et al., 2014). Also, it will be very important to realize this experiment on various wooden materials, in addition to on various moisture levels. The relations shown in the following figure were created using the designed application software, which operate on the basis of the designed mathematical model. 


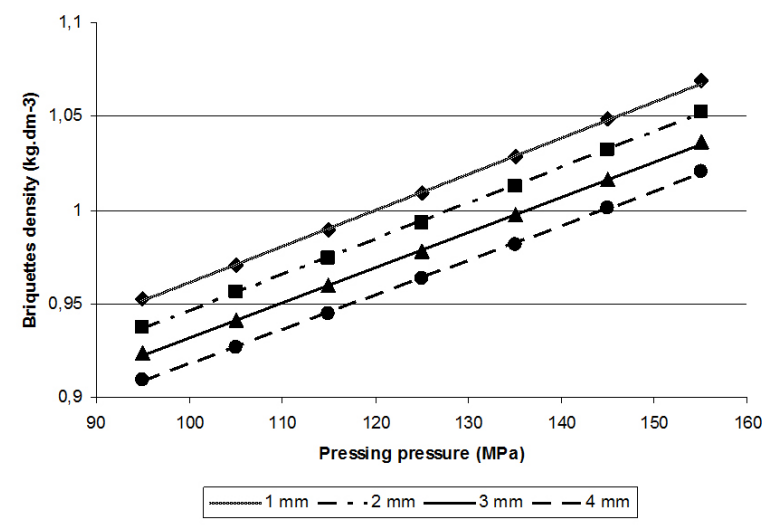

Figure 5.21: Dependence of briquette density on pressure at various fraction sizes $\left(T=85^{\circ} \mathrm{C} ; \mathrm{L}=2 \mathrm{~mm}\right)$.

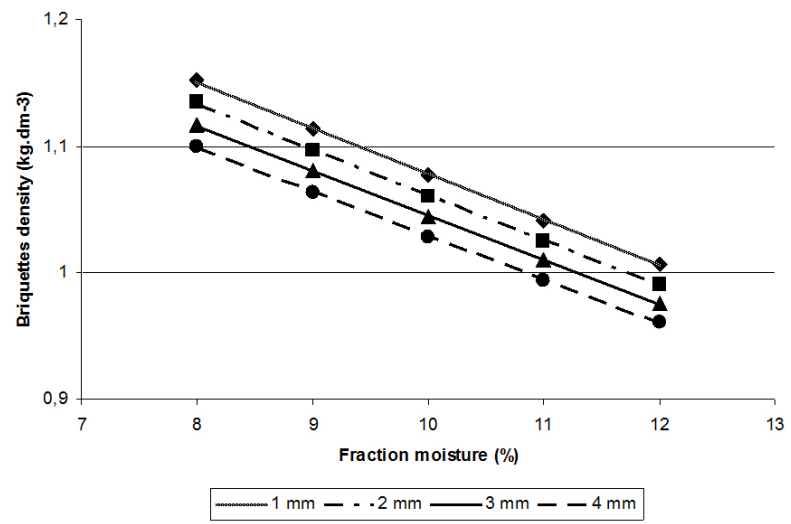

Figure 5.22: Dependence of briquette density on moisture content at various fraction sizes $\left(\mathrm{T}=85^{\circ} \mathrm{C}\right.$; p = 159 MPa) (Šooš, Matúš \& Križan, 2010; Križan, 2009). 